\title{
Management of Postprandial Hypotension in a Tetraplegic Patient after Cervical Spinal Cord I njury
}

\author{
Yong-Jun Lee, Sang-Hyun Han, Seung-Jae Hyun, Ki-Jeong Kim, Tae-Ahn Jahng \\ Department of Neurosurgery, Spine Center, Seoul National University Bundang Hospital, Seoul National University College of \\ Medicine, Seongnam, Korea
}

\begin{abstract}
Our aim was to present a case of postprandial hypotension in a tetraplegic patient with a cercal spinal cord lesion. A 43-year-old woman presented in the emergency room with tetraplegia after a motor vehicle crash. Radiologic studies showed dislocation at the C4-C5 level. Promptly, under general anesthesia, she underwent closed reduction, anterior cervical discectomy, and fusion at the C4-C5 level for stabilization. From the second day postoperatively, her systolic blood pressure was reduced from 120-150 $\mathrm{mmHg}$ to $40-60 \mathrm{mmHg}$ when she made a positional change or after she ate. We tried administering a very slow and continuous infusion rate of a liquid meal $(60 \mathrm{cc} / \mathrm{h})$, and it was very effective in controlling PPH. In rare cases of PPH in a tetraplegic patient with a cervical spinal cord lesion, a very slow and continuous infusion rate of a liquid meal $(60 \mathrm{cc} / \mathrm{h})$ may be one effective management method.
\end{abstract}

Key Words: Tetraplegia; Hypotension; Feeding methods

$\triangle$ Corresponding Author: Tae-Ahn Jahng, Department of Neurosurgery, Spine Center, Seoul National University Bundang Hospital, Seoul National University College of Medicine, 82, Gumi-ro 173 Beon-gil, Bundang-gu, Seongnam 13620, Korea. Tel: +82-31-787-7164, Fax: +82-31-787-4059, E-mail: taj@snu.ac.kr

\section{INTRODUCTION}

Postprandial hypotension (PPH) has been defined as a decrease in systolic blood pressure (BP) of $20 \mathrm{mmHg}$ or a decrease $<90$ $\mathrm{mmHg}$ from a pressure of $100 \mathrm{mmHg}$ within $2 \mathrm{~h}$ after a meal ${ }^{6}$. PPH occurs in elderly persons and in those with autonomic dysfunction, Parkinson disease, paraplegia, diabetes mellitus, tabes dorsalis, and ganglionic blockage ${ }^{3,6)}$.

There is a previous report about symptomatic PPH in a paraplegic patient with complete neurological deficits below the T3 segment ${ }^{3)}$ and an experimental article about the relationship between PPH and thoracic spinal cord damage ${ }^{2}$. These reports have stated that PPH cannot occur in tetraplegic patients with cervical cord injury. However, we report a case of symptomatic PPH in a tetraplegic patient after cervical cord injury and discuss its management.

\section{CASE REPORT}

A 43-year-old woman presented to our emergency room after a motor vehicle crash. On neurologic examination, she was tetraplegic. She had no pinprick or light touch sensation below the $\mathrm{C} 4$ level and had difficulty breathing. Plain radiographs showed facet dislocation at the C4-C5 level, suggesting a spinal

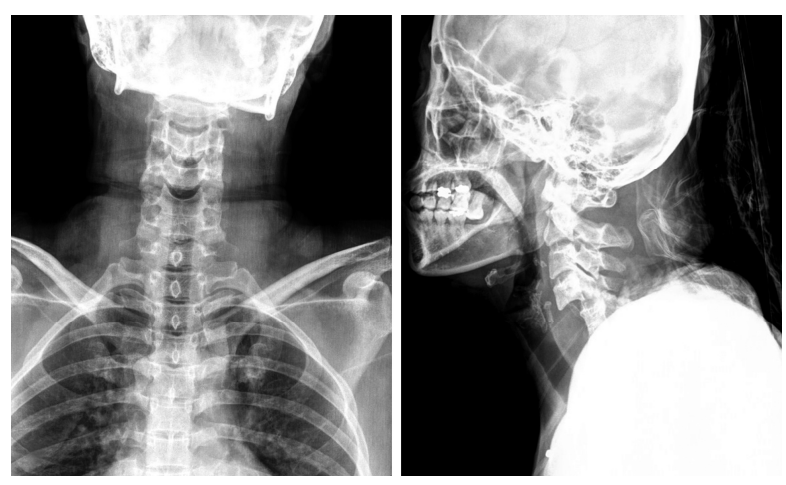

Fig. 1. Preoperative radiographs of the anteroposterior (A) and lateral (B) views showing dislocation of both facet joints at the C4-C5 level, and fracture of the spinous process and both lamina of C4.

cord lesion (Fig. 1). Magnetic resonance imaging (MRI) showed spinal cord contusion at the C3-C6 level (Fig. 2). Halter traction was gently applied with the patient under general anesthesia as the first step of treatment for closed reduction. After successful closed reduction, anterior discectomy at the C4-C5 level, anterior fusion with a cage filled with allo-bone graft, and anterior plate fixation at the C4-C5 vertebral body was performed (Fig. 3). Postoperatively, she was transferred to the intensive care 

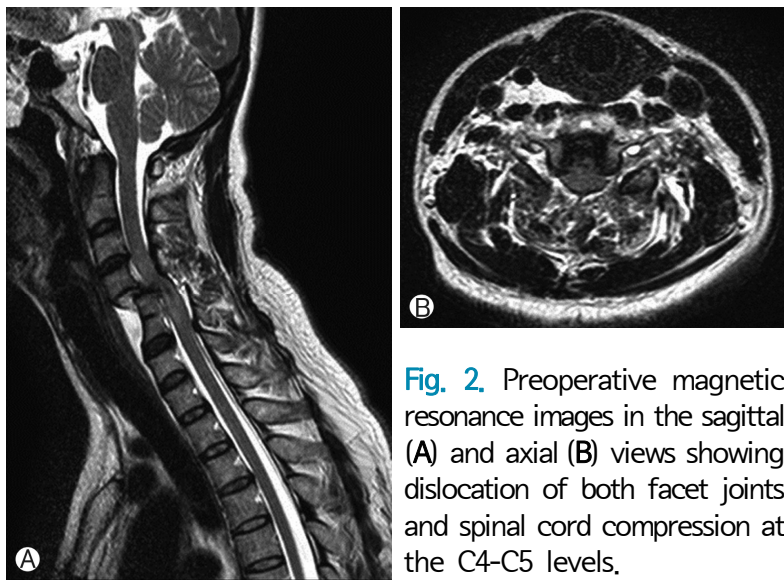

Fig. 2. Preoperative magnetic resonance images in the sagittal (A) and axial (B) views showing dislocation of both facet joints and spinal cord compression at the C4-C5 levels.

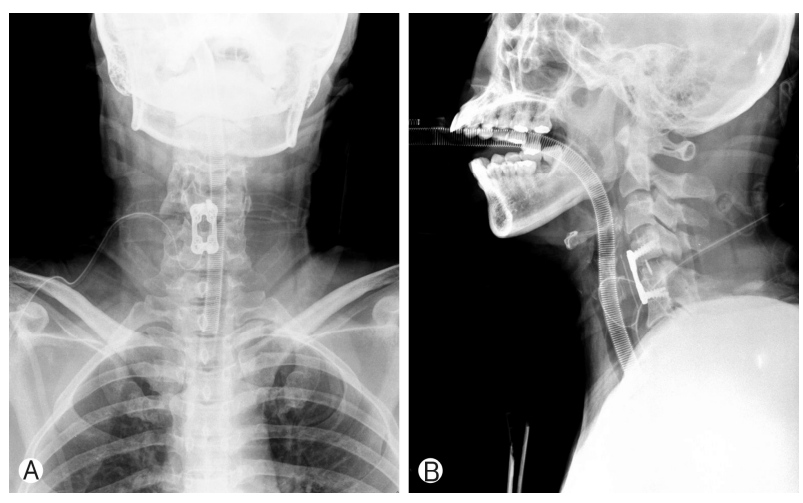

Fig. 3. Immediate postoperative radiographs in the anteroposterior (A) and lateral (B) views.

unit. To improve spinal cord perfusion, her BP was maintained between $140 / 80 \mathrm{mmHg}$ and $120 / 60 \mathrm{mmHg}$ with an infusion of dopamine $(10-15 \mu \mathrm{g} / \mathrm{kg} / \mathrm{min})$. From the second day postoperatively, her systolic blood pressure (SBP) decreased from 120-150 $\mathrm{mmHg}$ to $40-60 \mathrm{mmHg}$, and she lost consciousness. This phenomenon occurred frequently after position change from supine to head elevation, defecation, or ingestion of liquid meal through a Levine tube $(300 \mathrm{cc} / \mathrm{h})$. Therefore, we could not taper the dose of dopamine. She had no self-respiration until 6 days postoperatively, thus tracheostomy was performed. A portable ventilator was used for transfer to the general ward. Until 20 days postoperatively, the fluctuation in BP occurred continuously after a positional change or eating a meal. At first, it may have been helpful to use midodrine, an $\alpha 1$-receptor agonist, as a vasoconstrictor for postural hypotension and PPH. However, it had no effect on BP fluctuation after eating or positional changes. On 24 days postoperatively, when the patient's position was changed very gently, SBP was maintained with a decrease of about $20 \mathrm{mmHg}$. On 27 days postoperatively, we had decreased the continuous infusion rate of the liquid meal in stages until a modest rate for preventing a reduction in the SBP was identified. Ultimately, we determined that $60 \mathrm{cc} / \mathrm{h}$ was the maximum infusion rate for maintaining BP. After infusing liquid meals at $60 \mathrm{cc} / \mathrm{h}, \mathrm{PPH}$ did not occur anymore, and dopamine was tapered.

\section{DISCUSSION}

Mathias et al. ${ }^{10)}$ suggested that similar to patients with a dopamine $\beta$-hydroxylase deficiency, tetraplegic patients have the ability to activate vagal efferent pathways and may release peptides and other active vasoconstrictor substances from sympathetic nerve endings, thus PPH cannot occur in tetraplegic patients with a cervical cord lesion. Moreover, Catz et al. ${ }^{2,3}$ reported that in their experiment, $\mathrm{PPH}$ could not occur in tetraplegic patients with a cervical cord lesion, but it can occur in paraplegic patients with a thoracic spinal cord lesion. They suggested that the normal hemodynamic reaction during a liquid meal is mediated by the mid-thoracic spinal cord rather than by signals descending through the cervical spinal cord. However, our case suggests that PPH can occur in paraplegic and tetraplegic patients. There is no definite mechanism for $\mathrm{PPH}$ in tetraplegic patients.

There are several theories about PPH in elderly persons, but the mechanism has not been fully described. In elderly persons, the bowel blood volume increases by approximately $20 \%$ after a meal, and this is maintained longer than that in young persons ${ }^{7}$. The bowel blood volume is absent or blunted by the sympathetic response to systemic hypotension evoked by an intraduodenal glucose load ${ }^{5,11)}$. Furthermore, insulininduced blunting of the baroreflex sensitivity in elderly persons may affect $\mathrm{BP}^{1)}$. Similar to PPH in elderly persons, PPH in tetraplegic patients with a cervical spinal cord lesion may be due to the blunted sympathetic response to the increase in splanchnic blood flow after meal ingestion. Bowel movements in autonomic failure may induce PPH because of the intrathoracic pressure elevation". Therefore, it is easier for tetraplegic patients who do not have spontaneous breathing to be affected by bowel movements. Additionally, we hypothesized that in our patient, the mechanism for a normal hemodynamic reaction during a liquid meal was mediated by signals descending from the cervical spinal cord, and the patient had no ability to activate vagal efferent pathways like patients with a dopamine $\beta$-hydroxylase deficiency.

Nonpharmacologic modification or pharmacotherapy can be beneficial for treating $\mathrm{PPH}^{8)}$. Nonpharmacologic modifications include drinking water before meals, frequently eating small meals, and maintaining a recumbent or sitting position after meals. Drinking water before meals to increase the intravascular volume and changing positions were not effective for our patient. Only slowing the infusion rate of the liquid meals was effective. Pharmacotherapy includes caffeine, $\alpha$-glucosidase inhibitors, guar gum, and octreotide. However, $\alpha$-glucosidase inhibitors 
and guar gum can cause diarrhea, and diarrhea causes effects such as malnutrition and ileus through an electrolyte imbalance in tetraplegic patients. Octreotide can increase the splanchnic and peripheral vascular resistance ${ }^{4)}$, but it is expansive and has side effects of QT prolongation and pain at the injected location. The preprandial pressor effect of caffeine prevents $\mathrm{PPH}$, and caffeine is nontoxic, inexpensive, and widely available $^{6,8,11)}$.

\section{CONCLUSION}

In tetraplegic patients with a cervical spinal cord injury, PPH can occur; however, the slow and continuous infusion of a liquid meal is effective treatment of PPH.

\section{REFERENCES}

1. Appenzeller O, Goss J: Glucose and baroreceptor function: effects of oral administration of glucose on baroreceptor function in cerebrovascular disease and in other disorders with baroreceptor reflex block. Arch Neurol 23:137-146, 1970

2. Catz A, Bluvshtein V, Pinhas I, Akselrod S, Gelernter I, Nissel $\mathrm{T}$, et al.: Hemodynamic effects of liquid food ingestion in midthoracic paraplegia: is supine postprandial hypotension related to thoracic spinal cord damage? Spinal Cord 45:96-103, 2007
3. Catz A, Mendelson L, Solzi P: Symptomatic postprandial hypotension in high paraplegia. Case report. Spinal Cord 30:582-586, 1992

4. Hoeldtke RD, Davis K, Joseph J, Gonzales R, Panidis I, Friedman A: Hemodynamic effects of octreotide in patients with autonomic neuropathy. Circulation 84:168-176, 1991

5. Imai C, Muratani H, Kimura Y, Kanzato N, Takishita S, Fukiyama $\mathrm{K}$ : Effects of meal ingestion and active standing on blood pressure in patients $\geq 60$ years of age. The American Journal of Cardiology 81:1310-1314, 1998

6. Jansen RW, Lipsitz LA: Postprandial hypotension: epidemiology, pathophysiology, and clinical management. Annals of Internal Medicine 122:286-295, 1995

7. Lipsitz LA, Ryan SM, Parker JA, Freeman R, Wei JY, Goldberger AL: Hemodynamic and autonomic nervous system responses to mixed meal ingestion in healthy young and old subjects and dysautonomic patients with postprandial hypotension. Circulation 87:391-400, 1993

8. Luciano GL, Brennan MJ, Rothberg MB: Postprandial hypotension. Am J Med 123:281 e281-286, 2010

9. Mathias CJ: Autonomic dysfunction and hypotension, in Cardiovascular Medicine: Springer, pp1883-1910, 2007

10. Mathias CJ: Postprandial hypotension. Pathophysiological mechanisms and clinical implications in different disorders. Hypertension 18: 694-704, 1991

11. Ryan SM, Goldberger AL, Ruthazer R, Mietus J, Lipsitz LA: Spectral analysis of heart rate dynamics in elderly persons with postprandial hypotension. The American Journal of Cardiology 69:201-205, 1992 